\title{
Prenatal toxicity test of Morinda citrifolia (noni) fruit
}

\author{
Brett J. West, Chen X. Su and C. Jarakae Jensen \\ Research and Development, Tahitian Noni International, 737 East 1180 South, American Fork, Utah 84003, USA
}

(Received August 28, 2008; Accepted September 4, 2008)

\begin{abstract}
Morinda citrifolia (noni) fruit juice use has increased greatly within the past decade, with more than 80,000,000 liters being consumed world wide. With increasing widespread use and the potential use among pregnant women, a prenatal developmental toxicity test was conducted to further evaluate the safety of noni juice. Freeze-dried noni fruit puree from French Polynesia was administered daily by gastric intubation to separate dose groups $(\mathrm{n}=12)$ of pregnant Sprague Dawley rats at $1.72,3.43$, and $6.86 \mathrm{~g} / \mathrm{kg}$ body weight, with a control group receiving water in place of noni. The dose schedule was followed from the first day of gestation until one day prior to expected delivery, 21 days. There were no symptoms of toxicity in the pregnant dams. There was no difference between the control and any noni group in the number of live fetuses, resorptions, fetal weight and length, or skeletal abnormalities. No dead fetuses, gross external malformations, or internal organ defects were observed in any group. These findings do not indicate that toxicity from noni juice to developing embryos and fetuses is expected.
\end{abstract}

Key words: Noni, Morinda citrifolia, Prenatal toxicity

\section{INTRODUCTION}

Morinda citrifolia (noni) L. is a small tree that is widely distributed across the tropics, commonly known as Indian Mulberry or noni. Noni fruit has a history of use as food and for the promotion of health among Pacific Islanders, Southeast Asians, and those in the tropical regions of the Western Hemisphere (Morton, 1992). A commercial source of noni juice from French Polynesia, Tahitian Noni ${ }^{\circledR}$ Juice, was approved by the European Union as a novel food (European Commission, 2003). Consequently, the production and use of noni fruit juice has increased greatly (West et al., 2006b), with more than 80 million liters from French Polynesia alone being consumed worldwide since 1996 (European Food Safety Authority, 2006).

In Tongan folk medicine, the bark of the noni tree was included in an herbal tea used to treat morning sickness (Ostraff et al., 2000). The fruit juice has also been reported to be similarly effective (West, H.A. Personal communication, 2007). Noni fruit was also included in a traditional treatment for $k a h i$, a condition found among some Tongan women that involved infertility (Singh et al., 1984). With increasing widespread use of noni juice, and the potential use among pregnant women, a prenatal developmental toxicity test was conducted to further eval- uate its safety.

\section{MATERIALS AND METHODS}

Test material. Noni fruits were harvested in French Polynesia. These were allowed to fully ripen, then processed into puree and pasteurized at a good manufacturing certified fruit processing facility in Mataiea, Tahiti. This pasteurized noni fruit puree was evaluated in this study, as it is the major ingredient in the most commonly available commercial noni juice and is the specific material evaluated and approved by the European Union. The pasteurized puree was later freeze-dried to a 13-fold concentration.

Animals and dose schedule. During the test, three dose preparations of freeze-dried noni fruit puree were prepared by dissolving in distilled water at 17.2, 34.3, and $68.6 \mathrm{~g} / 100 \mathrm{ml}$. The dose preparations were administered by gastric intubation to pregnant dams at $10 \mathrm{ml} / \mathrm{kg}$ body weight, resulting in daily doses of $1.72,3.43$, and $6.86 \mathrm{~g} /$ $\mathrm{kg}$ body weight (bw). The highest dose is equivalent to approximately $90 \mathrm{ml}$ of noni fruit puree for juice $/ \mathrm{kg}$ bw, $10 \mathrm{ml}$ greater than the previously established no-observedadverse-effect-level (NOAEL). The animals assigned to the control group received distilled water. Healthy three month old Sprague Dawley rats were mated one male to

Correspondence: Brett J. West (E-mail: brett_west@tni.com) 
one female. At appearance of the vaginal plug, the first day of gestation (day 0), pregnant dams were separated and randomly assigned to a control group or one of the three dose groups. Each group contained 12 pregnant dams. The dosing schedule was started on Day 0 and followed till Day 20 of gestation, one day before the expected delivery of pups. Water and rodent feed were available to animals ad libitum.

Observation and measurements. Throughout the test, the animals were observed for symptoms of toxicity. Weights of pregnant dams were recorded on Days $0,7,12,16$, and 20 . On Day 20 of gestation, the dams were euthanized, and their uteri exposed surgically. The number of ovum implantations, embryo/fetal resorptions, live fetuses, and dead fetuses were recorded for each dam. Gross external fetal malformations of the head, spine, abdomen, chest, tail, limbs, and digits were recorded. Fetal weight and length were also recorded. Half the embryos were fixed in Bouin's solution for examination of internal organ defects. The other half were skinned and stained with $0.01 \%$ alizarin for examination of skeletal development. Macroscopic examination of fetuses included the trachea, esophagus, spinal cord, ventricles of the brain, eyes, nose, brain, diencephalons, palate, tongue, genitourinary organs, and visceral organs. Delayed skeletal development or abnormal arrangements and numbers in the bones of the skull, spinal column, limbs, sternum, ribs, and pelvis were recorded upon observation.

Means and standard deviations of continuous variables were calculated, with intergroup comparisons being made by analysis of variance. Differences in fetal survival, resorption, and abnormality rates, compared to the control group, were evaluated by the chi-square test.

\section{RESULTS AND DISCUSSION}

There were no significant intergroup differences in any observation or measurements. No symptoms of toxicity were evident in the pregnant dams in any group, and all gained appropriate weight during gestation (Fig. 1). Fetal measurements were comparable among all groups (Table 1). Healthy litter sizes were observed in all groups, with averages that ranged from 11.2-12 fetal pups/dam. No fetuses were found dead upon uterine examination. There was no increase in resorption rates in any of the noni groups, with embryo loss rates from 3.4-4.3\%. While not statistically significant, the loss rate among the controls was greater, at $5.9 \%$. No gross external malformations or internal organ defects were observed in fetuses from any group. No significant intergroup differences were seen in skeletal abnormalities, which were limited to delayed development of the skull and abnormal sternums. The average skeletal malformation rates in fetuses from the noni groups ranged from 15.6-20.8\%, with controls at $25.4 \%$. Mean fetal weight and length were essentially the same among all groups.

The findings of the current study suggest that the potential for toxicity from noni fruit to expectant mothers is very low. Such lack of toxicity has been evident in other toxicity tests. Subacute, subchronic, and genotoxicity tests did not reveal any evidence of toxicity from noni juice (Mancebo et al., 2002; West et al., 2006a; Westendorf

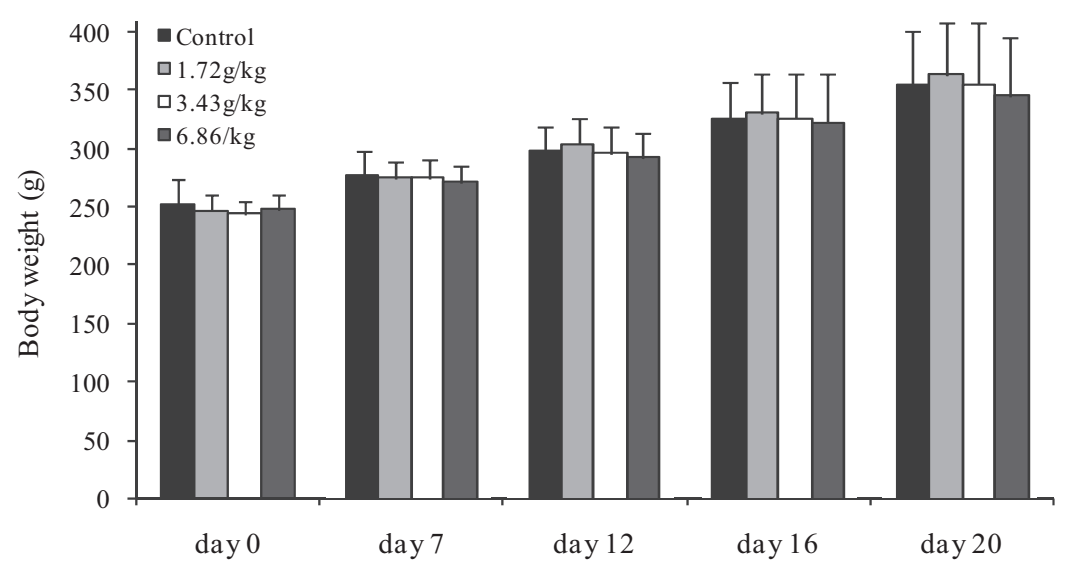

Fig. 1. Body weight of pregnant dams in control and noni treatment groups during gestation. Each column represents the mean \pm S.D. of twelve rats. 
Prenatal toxicity test of noni

Table 1. Observations and measurements of fetal health at Day 20

\begin{tabular}{|c|c|c|c|c|}
\hline Measurement & Control & $1.72 \mathrm{~g} / \mathrm{kg}$ & $3.33 \mathrm{~g} / \mathrm{kg}$ & $6.86 \mathrm{~g} / \mathrm{kg}$ \\
\hline live fetuses & 136 & 145 & 139 & 144 \\
\hline dead fetuses & 0 & 0 & 0 & 0 \\
\hline total resorptions & 8 & 5 & 6 & 5 \\
\hline gross external malformations & 0 & 0 & 0 & 0 \\
\hline mean fetal weight $(\mathrm{g}) \pm$ S.D. & $3.72 \pm 0.33$ & $3.67 \pm 0.30$ & $3.70 \pm 0.31$ & $3.76 \pm 0.37$ \\
\hline mean fetal length $(\mathrm{g}) \pm$ S.D. & $3.80 \pm 0.23$ & $3.77 \pm 0.24$ & $3.79 \pm 0.23$ & $3.80 \pm 0.23$ \\
\hline$\%$ skeletal abnormalities & 25.4 & 15.6 & 20.8 & 16.2 \\
\hline internal organ defects & 0 & 0 & 0 & 0 \\
\hline
\end{tabular}

S.D. = standard deviation

et al., 2007). The NOAEL from these studies was determined to be greater than $80 \mathrm{ml} / \mathrm{kg}$ bw. A previous antifertility study of plant extracts in mice revealed that subcutaneous injection of an aqueous extract from the noni plant did not have any adverse effect on litter sizes and produced no gross abnormalities in pups (Matsui et al., 1967). This experiment provided no evidence of toxicity to the developing embryo/fetus from noni fruit.

\section{ACKNOWLEDGMENT}

The current study was conducted in collaboration with the Nutrition and Food Safety Institute of the Chinese Disease Prevention and Control Center.

\section{REFERENCES}

European Commission (2003): 2003/426/EC: Commission Decision of 5 June 2003 authorising the placing on the market of 'noni juice' (juice of the fruit of Morinda citrifolia L.) as a novel food ingredient under Regulation (EC) No 258/97 of the European Parliament and of the Council. O.J.E.U., L144, 12.

European Food Safety Authority (2006): Opinion on a request from the Commission related to the safety of noni juice (juice of the fruits of Morinda citrifolia). E.F.S.A. J., 376, 1-12.

Mancebo, A., Scull, I., Gonzales, Y., Arteaga, M.E., Gonzales, B.O., Fuentes, D., Hernandez, O. and Correa, M. (2002): Ensayo de toxicidad a dosis repetidas (28 dias) por via oral del extracto acuoso de Morinda citrifolia en rata Sprague Dawley. Rev. Toxicol., 19, 73-77.

Matsui, A.S., Rogers, J., Woo, Y.K. and Cutting, W.C. (1967): Effects of some natural products on fertility in mice. Med. Pharmacol. Exp., 16, 414-424.

Morton, J.F. (1992): The ocean-going noni, or Indian Mulberry (Morinda citrifolia, Rubiaceae) and some of its 'colorful' relatives. Econ. Bot., 46, 241-56.

Ostraff, M., Anitoni, K., Nicholson, A. and Booth, G.M. (2000): Traditional Tongan cures for morning sickness and their mutagenic/toxicological evaluations. J. Ethnopharmacol., 71, 201209.
Singh, Y.N., Ikahihifo, T., Panuve, M. and Slatter, C. (1984): Folk medicine in Tonga. A study on the use of herbal medicines for obstetric and gynaecological conditions and disorders. J. Ethnopharmacol., 12, 305-329.

West, B.J., Jensen, C.J., Westendorf, J. and White, L.D. (2006a): A Safety Review of Noni Fruit Juice. J. Food Sci., 71, 100-106.

West, B.J., Tolson, C.B., Vest, R.G., Jensen, S. and Lundell, T.G. (2006b): Mineral variability among 177 commercial noni juices. Int. J. Food Sci. Nutr., 57, 556-558.

Westendorf, J., Effenberger, K., Iznaguen, H. and Basar, S. (2007): Toxicological and analytical investigations of noni (Morinda citrifolia) fruit juice. J. Agric. Food Chem. 55, 529-537. 